\title{
Article \\ Effects of Spatial Elements of Urban Landscape Forests on the Restoration Potential and Preference of Adolescents
}

\author{
Linjia Wu ${ }^{1}$, Qidi Dong ${ }^{1}$, Shixian Luo ${ }^{2}{ }^{-}$, Wenyuan Jiang ${ }^{1}$, Ming Hao ${ }^{1}$ and Qibing Chen ${ }^{1, *}$ \\ 1 College of Landscape Architecture, Sichuan Agricultural University, Chengdu 611130, China; \\ wulinjia0716@163.com (L.W.); d13402887131@foxmail.com (Q.D.); Cheungyuan070@126.com (W.J.); \\ haoo0617@163.com (M.H.) \\ 2 Graduate School of Horticulture, Chiba University, Chiba 263-8522, Japan; 19hd4106@student.gs.chiba-u.jp \\ * Correspondence: cqb@sicau.edu.cn
}

Citation: Wu, L.; Dong, Q.; Luo, S.; Jiang, W.; Hao, M.; Chen, Q. Effects of Spatial Elements of Urban Landscape Forests on the Restoration Potential and Preference of Adolescents. Land 2021, 10, 1349. https://doi.org/ 10.3390/land10121349

Academic Editor: Eusebio Cano Carmona

Received: 17 November 2021 Accepted: 4 December 2021 Published: 7 December 2021

Publisher's Note: MDPI stays neutral with regard to jurisdictional claims in published maps and institutional affiliations.

Copyright: (c) 2021 by the authors. Licensee MDPI, Basel, Switzerland. This article is an open access article distributed under the terms and conditions of the Creative Commons Attribution (CC BY) license (https:// creativecommons.org/licenses/by/ $4.0 /)$.

\begin{abstract}
City green space can promote people's health and aesthetic satisfaction; however, most extant research focuses on suburban forests and urban parks. Urban landscape forests have important ecological and aesthetic value for urban environments. This study conducted a visual stimulation to examine the impact of four common spatial element combinations in urban landscape forests on teenagers' recovery potential and preference. The results indicate that urban landscape forests had positive physiological and psychological effects on adolescents, including decreased blood pressure, improved heart rate, reduced anxiety, and improved recovery ability. Diastolic blood pressure relief performance was better among males than females. In addition, a stepwise linear regression analysis was performed to explore the quantitative relationship between spatial elements and recovery and preference values. The results demonstrate that water elements were a significant predictor in the quantitative relationship between spatial elements in landscape forests and restoration and preference values. Terrain, flower, and shrub elements did not have a significant effect on overall restoration and preference values. This study highlights the intervention value of urban landscape forests in promoting the health and well-being of adolescents, with implications for future planning and design of urban landscape forests.
\end{abstract}

Keywords: urban landscape forests; spatial element; restoration potential and preference; adolescents

\section{Introduction}

Different elements of the urban natural environment constitute a variety of urban landscapes [1,2]. In the context of large-scale urbanization, a public health strategy based on natural environmental components in urban landscapes may have special value to urban populations [3]. Good urban natural planning is considered an effective method to solve residents' health problems $[4,5]$ and prevent health risks in the process of rapid urbanization [6]. Schools are under high pressure in the city. Teenagers constitute the main user group of schools and may suffer from the pressure of academic examination and work in their daily life [7]. Improving the physical environment, including the green environment, particularly outdoor open space, during adolescence is important to effectively and positively affect the health and well-being of students [8-11]. Therefore, the benefits of landscape features in urban settings for the physical and mental health of young people should be explored [12] and used to guide greening construction [4]. As the physical environment in the city can be selected and changed [13], urban greening decision-makers and planners should understand, in their limited and common natural experience [14,15], the types and characteristics of green spaces with high restoration potential, which promote health the most [16].

Natural capital plays an irreplaceable positive role in sustainable development. Urban landscape forests (ULFs), as a part of urban natural capital, are not only places to create a positive image and beauty for people's lives and sightseeing but can also be viewed 
as projects to realize urban beautification $[17,18]$. In the past, urban afforestation was mainly based on the ecology, economy, and aesthetics of buildings $[19,20]$. With the field of urban greening governance showing a shift from a preliminary descriptive scope to specific pattern research [21], an increasing number of studies on the implementation of blue-green space strategies based on green infrastructure [22] have confirmed the importance of non-material benefits in urban forestry [23-25], including improving human well-being [21]. This includes related discussions in the two research fields of green space restoration and preference. The environmental self-regulation hypothesis holds that the application of environmental strategies serves as an environmental support for self and emotional regulation [26-28], and natural places provide high-quality recovery experiences [29]. In the process of restoration, there is a relationship between environmental preferences and socio-physical characteristics [30]. The literature in various landscape research disciplines has utilized psychophysical and psychological methods and demonstrated that the restoration potential of forest spaces is related to preferences [30]. Teenagers prefer natural environment activities in forests [28,31]. In addition, the number of trees in the forest is positively correlated with preferences [32] and restoration [33,34]. However, previous studies on resilience and preference mostly focus on suburban forest and park green spaces, with limited focus on youth groups in ULFs.

Studies on spatial elements of the existing urban green environments indicate that changes in characteristics or variables of landscape elements result in differences in the performance of health promotion [16,35-37], which can effectively strengthen the form of natural participation to create an environment with higher restorative potential [38]. Studies have shown that water, terrain, and plants are the most predictive factors of restoration $[2,33]$. However, there remains a lack of studies on the restoration differences and preferences based on the combination of specific elements in ULFs. The user's perception of the landscape is largely obtained by observing the space [39]. Visual information is collected, transmitted, and combined through a series of transmissions to reach the parietal, temporal, and frontal cortical centers for interpretation and response [40]. In the field of landscape design, researchers have paid increasing attention to exploring landscape spatial characteristics, human visual behavior, and psychological cognition through visual stimulation [39]. The formation of the result of human perception of space is a dynamic accumulative process of the formation of observational landscape space. Different spatial characteristics and constituent elements have an interaction effect on the viewing behavior and psychological perception of participants [39]. Forest environments under real-world conditions are a complex combination of multisensory information integration and expected mechanisms [41]. However, urban planning decision-makers are limited in obtaining different positive sensory stimuli through natural planning to improve biodiversity by the difficulty of quantifying nature outside of vision [42]. When the stimuli of smell [43,44], hearing [45], and touch [46,47] are presented alone, the psychological effects differ. Therefore, this study focuses on the exploration of the visual stimulation of the landscape to explore the restoration and aesthetic differences of urban forests based on one-way visual senses of various spatial elements.

Previous studies confirmed the possibility of the interaction between visual stimulation and the restoration potential of different landscape feature variables. However, studies on the effect of different elements in ULFs on the physical and mental recovery of adolescents and studies examining which landscape element variables have the most recovery potential and preferences for adolescents remain scarce. Forest landscapes are one of the most common landscape types that people experience [48]. Therefore, based on previous research on the restorative effect of and preference for urban green spaces and urban forests, this study proposed the following two hypotheses:

Hypothesis 1 (H1): ULFs have a positive impact on the physical and mental recovery of adolescents. 
Hypothesis 2 (H2): In evaluating the health benefits of and preference for ULFs composed of different spatial elements, water, flowers, and shrubs are significant predictors.

\section{Materials and Methods}

\subsection{Participants}

This study recruited 120 participants (60 men and 60 women) from students in different majors in Sichuan Agricultural University using campus posters and online advertisements. The average age was $21.34 \pm 2.77$ years. The average body mass index was $23.44 \pm 3.24$. Participants were assigned numbers $\mathrm{k} 1-\mathrm{k} 120$ in sequence. The inclusion criteria were: (1) being between 18 and 25 years old; (2) being healthy and having no history of physical or mental illness; (3) voluntarily signing an informed consent form before the experiment; and (4) agreeing to not smoke, drink, or exercise the day before the experiment. The experimental procedure of this study was conducted in accordance with the ethical standards of the National Research Committee and in line with the Helsinki Declaration and was approved by the local ethics committee of the School of Landscape Architecture of Sichuan Agricultural University.

\subsection{Stimulus Selection}

Two thirds of the spatial perception caused by the stimulating effect of space on the human body comes from vision [49]. Image research is an economic and convenient research tool [50] with no significant differences from natural stimulation [51]. Previous studies revealed four common visual factors in urban green space: terrain, water, flowers, and shrubs $[1,2,16,34,52]$. This study used only ornamental plants in the selection of spatial element combination materials to avoid potential deviations caused by participants considering additional material benefits [53]. Most of China is located in temperate and subtropical zones, and the landscape color visibly changes. Some studies have shown that yellow leaves are more popular with recreationists [54]. A photograph of a pure ginkgo forest in autumn was selected as the original photo (termed group B), and the interference of non-structural factors was minimized by comparison with mixed forests [55]. Ginkgo biloba L. is the most common seasonal greening plant material in Southwest China. The ginkgo forest at the photo site was artificially created and well maintained, eliminating the uncertain factors caused by unfamiliar experimental materials. In addition, two common scenes in cities, namely traffic and a city square, were added as a research transition (termed group A). Four groups of spatial elements were created by deleting four visual features. Visual elements were divided into four groups based on an increasing combination: C, D, E, and F. This study used a total of 18 images as stimulation materials (Figure 1).

\subsection{Study Location and Procedures}

The research was conducted in the multimedia room of Sichuan Agricultural University from September 25 to September 31, 2021. The indoor temperature and humidity of the two classrooms used during the research period were maintained at $19-24{ }^{\circ} \mathrm{C}$ and $40-45 \%$, which are the most comfortable temperature and humidity ranges for people. The experiment was divided into two parts. First, participants entered the prepared classroom individually, completed a questionnaire regarding their basic sociodemographic characteristics, and listened to an explanation about the experimental procedure. Subsequently, they sat quietly for 5 minutes to eliminate external effects. Following this, they entered the stress induction stage. Previous studies demonstrated that students feel anxious when speaking foreign languages. This study used 5 minutes of English vocabulary dictation from TOEFL and professional level 8, which is above the usual level of difficulty for teenagers, to induce stress. After completing the State Trait Anxiety Inventory State (SIAI-S) and Restorative Results Scale (ROS) questionnaires, pre-test measurements of physiological indicators, including blood pressure, blood oxygen, and pulse, were conducted by the staff. In the recovery phase, the participants were taken to the multimedia room next door 
and viewed the experimental photographed image of the urban landscape forest (group B) in a sitting position, as psychological effects based on vision occur after $5 \mathrm{~s}$ [56]. The image projection time was $5 \mathrm{~min}$. After being asked to fully experience the image, the participants viewed the image quietly. During this period, the participants could not use electronic equipment, talk, or eat. After that, the participants completed the SIAI-S and ROS questionnaires, and physiological indexes were recorded again. The first part of the experiment was approximately $20 \mathrm{~min}$ in length.

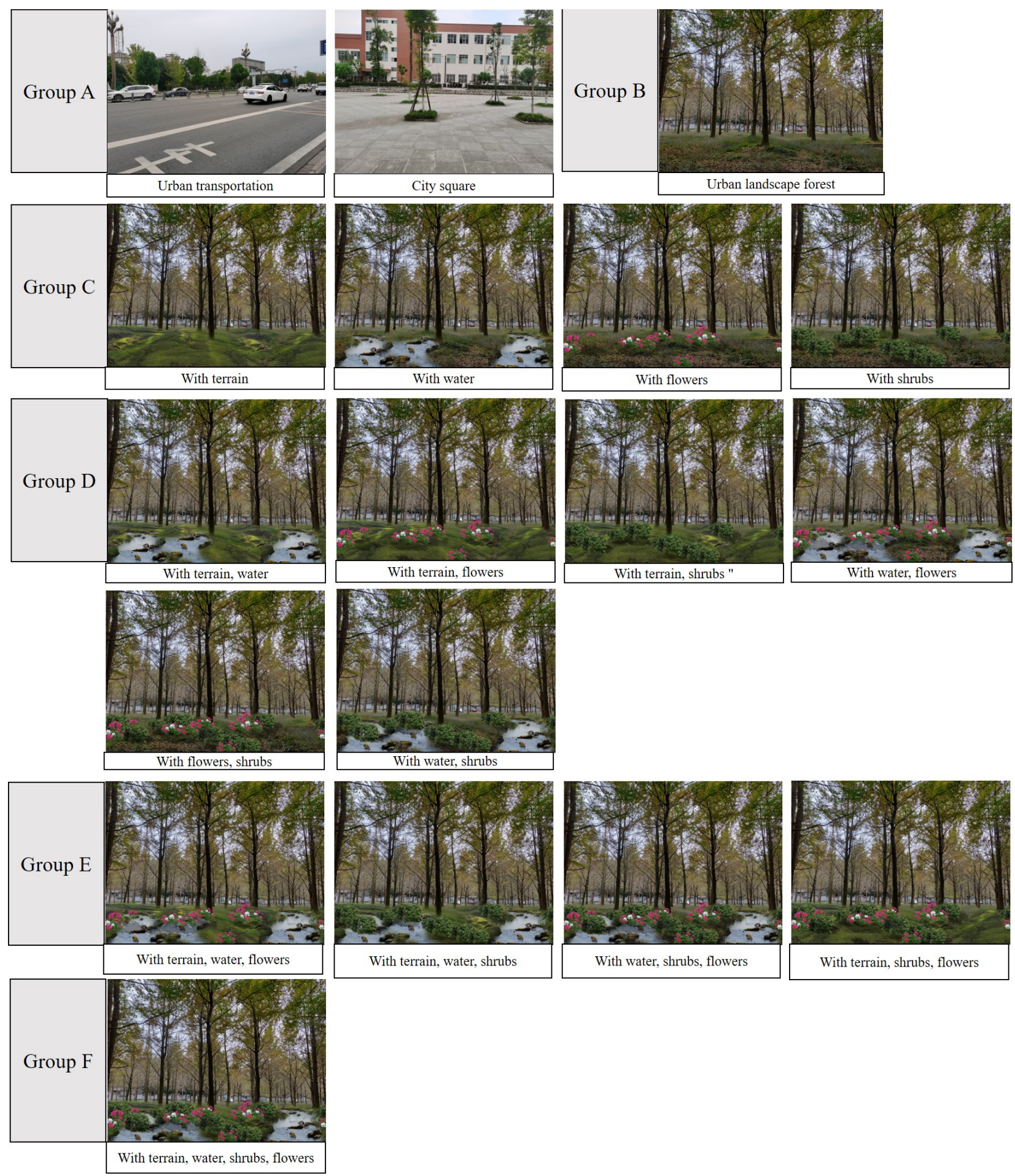

Figure 1. The eighteen images for experimental visual stimulation. 
During the second part of the experiment, the participants were asked to score the recoverability of and preference for six groups of 18 images composed of urban traffic, urban squares, urban landscape forests, and different landscape elements. The automatic projection time for each image was $15 \mathrm{~s}$. After fully observing the image and scoring, participants manually clicked the mouse button to show the next image, proceeding until all images were scored. After completion, the participants were asked to rest for $5 \mathrm{~min}$ to eliminate the impact of the experiment. After the experiment, the participants received a reward (30RMB). The experiment was arranged based on the numerical sequence of participants. Each experiment was $35 \mathrm{~min}$ in length (Figure 2).

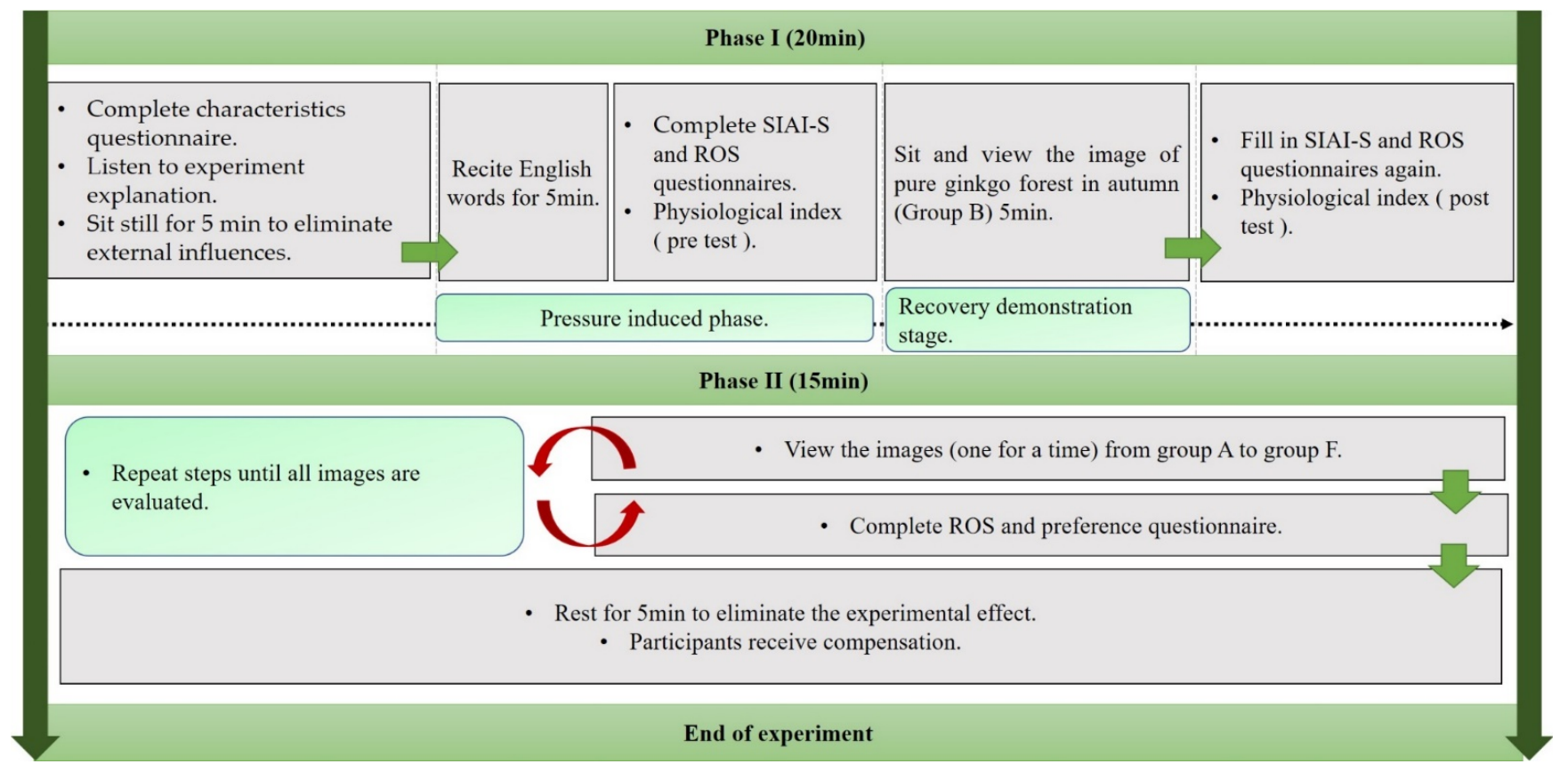

Figure 2. Experimental steps.

\subsection{Measurements}

\subsubsection{Physiological Measurement}

Physiological measurements evaluate the objective response to stimulation [57], which usually includes brain activity, autonomic nerve activity, and endocrine activity. In this study, an arm sphygmomanometer (hem-6322t, Omron, Tokyo, Japan) was used to measure systolic blood pressure $(\mathrm{mmHg})$, diastolic blood pressure $(\mathrm{mmHg})$, and pulse, which were used to objectively reflect the activities of the human sympathetic nervous system (SNS) and parasympathetic nervous system (PNS) $[58,59]$ and the changes in cardiovascular activities caused by emotional changes [60]. Peripheral oxygen saturation (SpO2) was measured with a finger clip oximeter (Yuwell, Jiangsu, China).

\subsubsection{Psychological Measurement}

Two psychological questionnaires were used to measure the restoration potential of ULFs and different spatial elements. The State Trait Anxiety Inventory (STAI) is a self-report tool that measures current anxiety symptoms and degrees [61,62], including state and trait anxiety $[2,63]$. The purpose of this study was to detect the anxiety levels of participants after viewing urban landscape forest images. Therefore, this study used the STAI state anxiety (STAI-S) section instead of the 40-item scale. This scale is considered reliable and effective [41]. It includes six items: "I feel calm", "I am nervous", "I feel depressed", "I am relaxed", "I am satisfied", and "I am worried". Each item was evaluated using a four-point Likert scale ( $1=$ not at all; $4=$ very). Values for nervous, depressed, and worried were reverse-scored. 
The ROS is a reliable tool for assessing the level of recovery [64]. It includes six items: "I feel restored and relaxed", "I feel calm", "I have energy for my every day routines", "I feel focused and alert", "I can forget every day words", and "my thoughts are clear". Each item was evaluated using a seven-point Likert scale ( $1=$ very unlikely; $7=$ very likely).

\subsubsection{Preference Measurement}

This study collected data on participants' preferences for different elements of forest landscape space using a five-point Likert scale to evaluate how much they liked this scene or environment ( 0 = "I do not like it at all"; 4 = "I like it very much").

\subsection{Statistical Analysis}

SPSS 25.0 (IBM, Armonk, New York, USA) was used for statistical analysis. The $t$-test was conducted in accordance with a normal distribution. The paired $t$-test was used to analyze the average and significance of the physiological and psychological data of the participants and the groups of men and women. If the intermediate effect was significant, the Bonferroni test was used as a post-test. Stepwise multiple linear regression was used to analyze the quantitative relationship between the four spatial elements and recovery value and preferences. On the premise of meeting the multicollinearity of residuals, the analysis of variance, and a normal distribution, the different visual components were dummy-coded as independent variables, while restorative and preference values were dependent variables. This study explored the significant predictions of different spatial element stimuli on restorative and preference values.

\section{Results}

\subsection{Physiological Results}

\subsubsection{Effect on Blood Pressure}

Figure 3 shows the statistical difference between systolic and diastolic blood pressure $\left(p<0.05^{*}, p<0.01^{* *}, p<0.001^{* * *}\right)$. After viewing the urban landscape forest pictures, the systolic blood pressure (before viewing $=108.40 \pm 22.27$; after viewing $=102.18 \pm 10.40$, $\mathrm{p}<0.001$ ) and diastolic blood pressure (before viewing $=63.88 \pm 7.51$; after viewing $=61.26 \pm 6.72, \mathrm{p}<0.01)$ decreased significantly. The blood pressure decreased significantly in men before and after viewing the urban landscape forest pictures $(p<0.001)$, while there was no significant difference in women's diastolic blood pressure before and after viewing the urban landscape forest pictures (before viewing $=62.53 \pm 6.39$; after viewing $=61.03 \pm 5.09, p=0.06$ ).

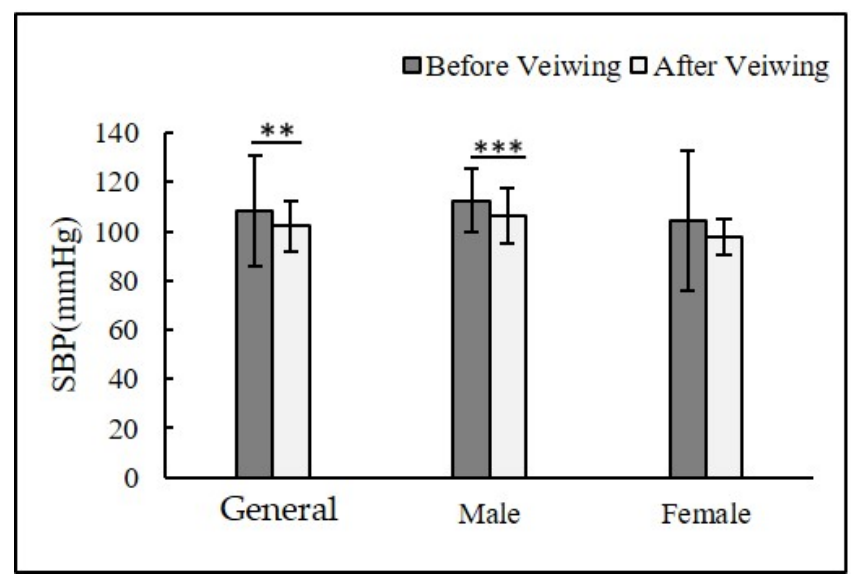

(a)

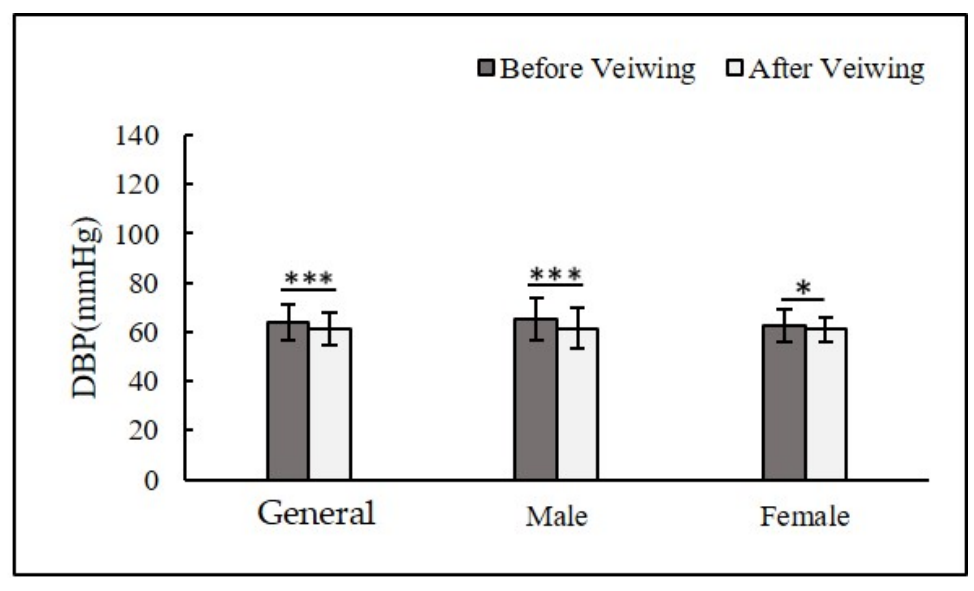

(b)

Figure 3. Changes in blood pressure before and after viewing the landscape forest pictures $\left(\mathrm{n}=120 ;\right.$ mean $\pm \mathrm{SD} ;{ }^{*} p<0.05$; ${ }^{* *} p<0.01 ;{ }^{* * *} p<0.001$; verified by a paired $t$-test): (a) systolic blood pressure changes; (b) diastolic blood pressure changes. 


\subsubsection{Effect on Blood Oxygen}

As shown in Figure 4, the overall blood oxygen value of the participants decreased before and after viewing the urban landscape forest pictures; however, the difference was not significant (before viewing $=98.14 \pm 17.99$; after viewing $=96.24 \pm 1.95, p=0.26$ ). The blood oxygen value of men (before viewing $=96.46 \pm 1.68$; after viewing $=96.22 \pm 1.78$, $p=0.20$ ) and women (before viewing $=99.82 \pm 25.39$; after viewing $=96.26 \pm 2.12, p=0.28$ ) did not change significantly before and after viewing the urban landscape forest pictures.

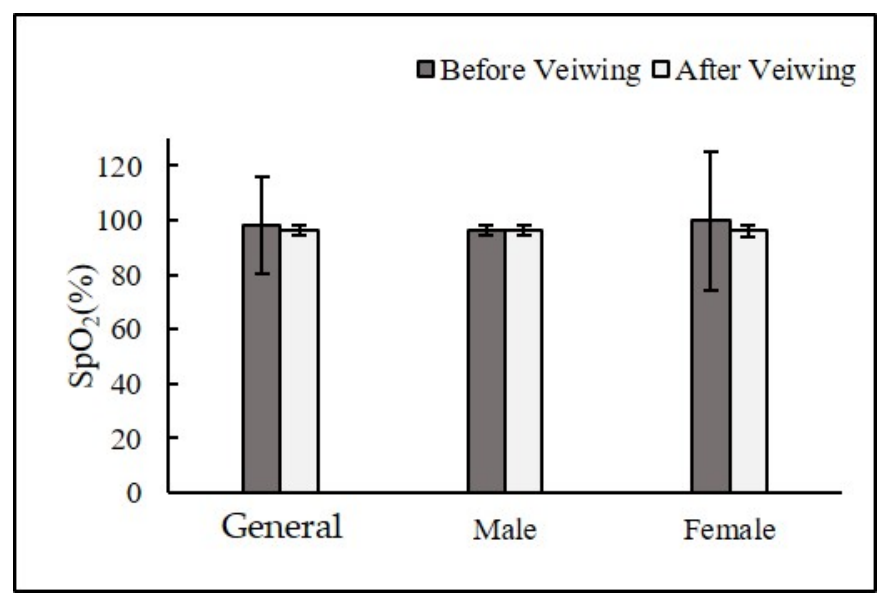

Figure 4. Changes in blood oxygen before and after viewing the landscape forest pictures ( $\mathrm{n}=120$; mean $\pm \mathrm{SD} ;{ }^{*} p<0.05 ;{ }^{* *} p<0.01 ;{ }^{* * *} p<0.001$; verified by a paired $t$-test).

\subsubsection{Effect on Heart Rate}

As shown in Figure 5, the overall heart rate of the participants before and after viewing the landscape forest pictures decreased significantly (rate of change $=4.44$, $p<0.001$ ). The average heart rate of male participants decreased by $3.87 \mathrm{bmp}$ (before viewing $=98.14 \pm 17.99$; after viewing $=96.24 \pm 1.95, p<0.001$ ), while the average heart rate of female participants decreased by $5.02 \mathrm{bmp}$ (before viewing $=98.14 \pm 17.99$; after viewing $=96.24 \pm 1.95, p<0.001)$. The decrease was significant in both men and women, indicating that the heart rate was significantly reduced after viewing the experimental pictures.

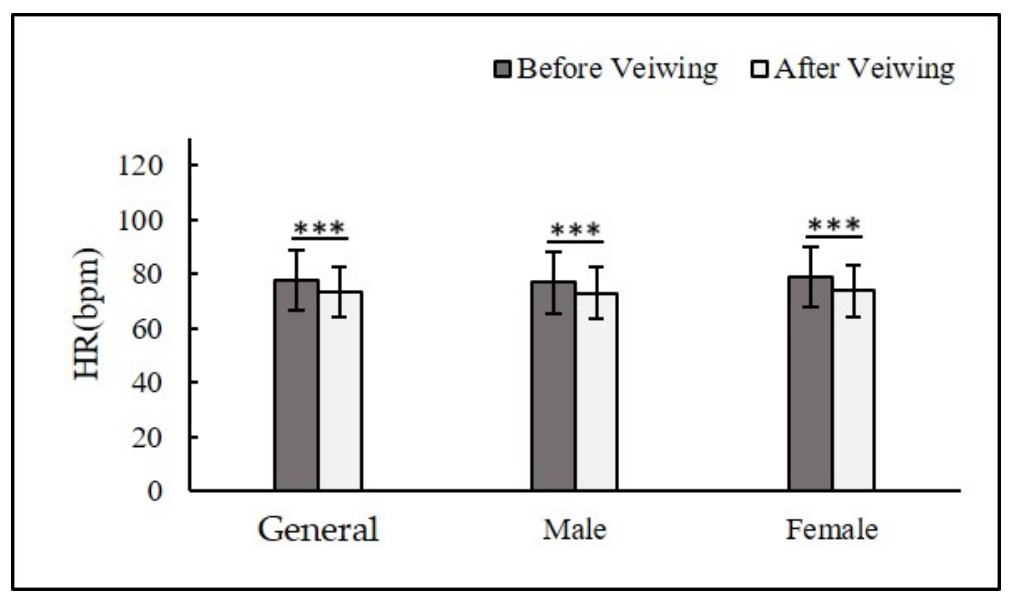

Figure 5. Changes in heart rate before and after viewing the landscape forest pictures $(\mathrm{n}=120$; mean $\pm \mathrm{SD} ;{ }^{*} p<0.05 ;{ }^{* *} p<0.01 ;{ }^{* * *} p<0.001$; verified by a paired $t$-test). 


\subsection{Psychological Results}

\subsubsection{SIAI-S Results}

Table 1 shows the $t$-test results of paired samples, which test the psychological differences between pre-test and post-test when viewing images of a ginkgo forest landscape with different compositions. Compared with the pre-test SIAI-S value (general $=2.96 \pm 0.67$ ), the post-test SIAI-S value (general $=2.40 \pm 0.39$ ) revealed a very significant decrease in anxiety $(\mathrm{t}=8.49, p<0.001)$. The decrease in anxiety among female participants was -0.58 , which was greater than that among male participants $(-0.53)$.

Table 1. Changes in the SIAI-S scores before and after viewing the urban landscape forest pictures.

\begin{tabular}{ccccccccc}
\hline \multirow{2}{*}{ Objects } & \multicolumn{2}{c}{ Pre-Test } & \multicolumn{2}{c}{ Post-Test } & \multirow{2}{*}{$\boldsymbol{t}$} & \multicolumn{2}{c}{$\begin{array}{c}\text { Rate of } \\
\text { Change }\end{array}$} \\
\cline { 2 - 4 } & Mean & S.D. & Mean & S.D. & & & & \\
\hline General & 2.96 & 0.67 & 2.4 & 0.39 & & 8.489 & $0.00^{* * *, 1}$ & -0.56 \\
Male & 2.98 & 0.64 & 2.45 & 0.4 & & 5.655 & $0.00^{* * *}$ & -0.53 \\
Female & 2.93 & 0.71 & 2.35 & 0.4 & & 6.313 & $0.00^{* * *}$ & -0.58 \\
\hline
\end{tabular}

\subsubsection{ROS Results}

Table 2 shows the restorative impact of viewing urban landscape forest pictures on teenagers. The average value of the post-test ROS shows that six recovery emotions in adolescents significantly improved (before viewing $=4.11 \pm 0.85$; after viewing $=4.98 \pm 1.07$, $p<0.001)$. The change in recovery values of men and women before and after viewing the urban landscape forest pictures was highly significant $(p<0.001)$.

Table 2. Changes in ROS scores before and after viewing the urban landscape forest pictures.

\begin{tabular}{|c|c|c|c|c|c|c|c|}
\hline \multirow{2}{*}{ Objects } & \multicolumn{2}{|c|}{ Pre-Test } & \multicolumn{2}{|c|}{ Post-Test } & \multirow{2}{*}{$\mathbf{t}$} & \multirow{2}{*}{$p$} & \multirow{2}{*}{$\begin{array}{l}\text { Rate of } \\
\text { Change }\end{array}$} \\
\hline & Mean & S.D. & Mean & S.D. & & & \\
\hline General & 4.11 & 0.85 & 4.98 & 1.07 & -9.07 & $0.00^{* * *, 1}$ & 0.87 \\
\hline Male & 4.17 & 0.63 & 5.08 & 0.96 & -6.80 & $0.00^{* * *}$ & 0.91 \\
\hline Female & 4.04 & 1.04 & 4.88 & 1.17 & -6.01 & $0.00^{* * *}$ & 0.84 \\
\hline
\end{tabular}

\subsection{Recovery Value and Preference Scores of Different Spatial Elements}

The recovery potential scores of the different spatial elements were calculated (Figure 6). The highest recovery value scores were for pictures 8 (5.04 \pm 1.07$)$ and $15(5.01 \pm 1.44)$, with the added spatial elements of water and terrain and water and terrain and shrub, respectively. The scores of urban traffic in picture $1(3.72 \pm 0.94)$ and the urban square in picture $2(3.92 \pm 1.07)$ were the lowest. For preferences, the top three were picture 5 $(3.30 \pm 0.72)$, picture $8(3.13 \pm 0.85)$, and picture 15 (3.01 \pm 0.94$)$, with the added spatial elements of water, water and terrain, and water and terrain and shrub, respectively.

\subsection{Recovery and Preference Values of Different Spatial Elements}

Stepwise multiple linear regression analysis was used to explore the quantitative relationship between different spatial elements, recovery values, and preferences. Following previous studies [34], the combination of four different spatial elements was quantified using virtual coding: terrain $=1$, without terrain $=0$, with natural water $=1$, without natural water $=0$, with flowers $=1$, without flowers $=0$, with shrubs $=1$, and without shrubs $=0$. The average value of six independent variables was taken as the ROS value, and the average value was taken as the preference score. The Kolmogorov-Smirnov test was used to check for multicollinearity, ANOVA, and multicollinearity of the residuals. The results show that the overall recovery $(z=0.115, p=0.200)$ and preference $(z=0.096$, 
$p=0.200$ ) values followed a normal distribution. After deleting the factors of the multicollinearity problem in the model, the significant factors for the restoration and preference values were obtained (Table 3). Water was a significant predictor of visual stimulation of landscape forests. The landscape forest image with a water element had a positive impact on the participants, while the impact of other elements was not significant.

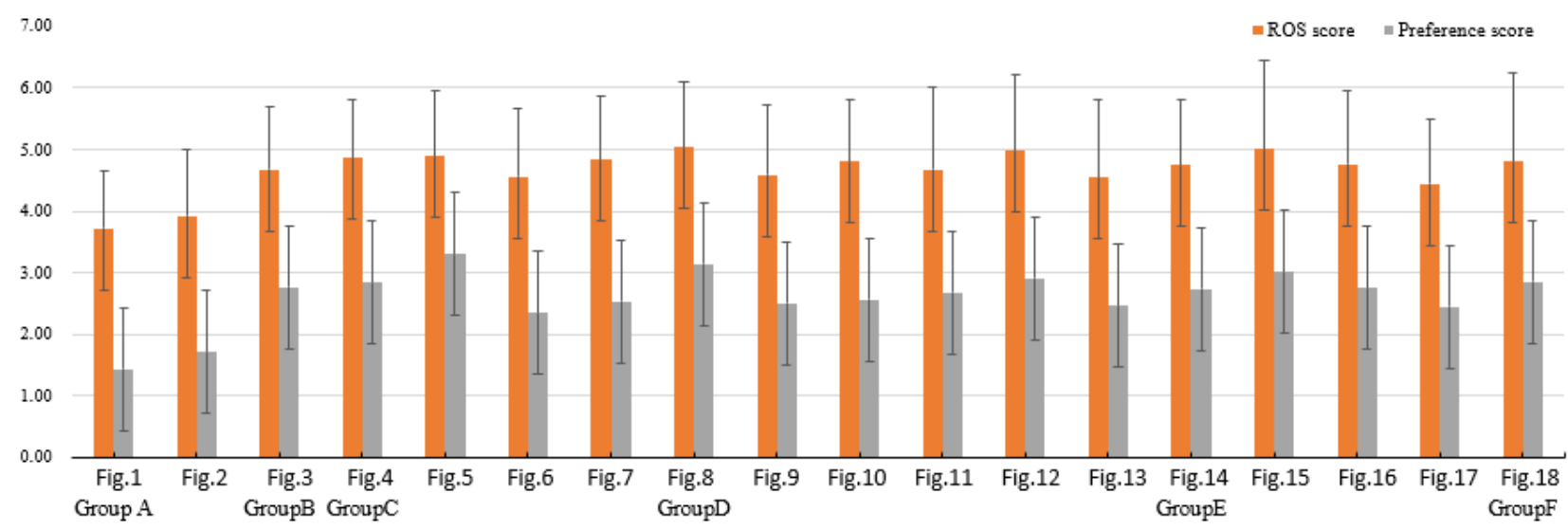

Figure 6. Recovery and preference values of different spatial elements.

Table 3. Significant influence of different spatial element stimuli on recovery and preference values.

\begin{tabular}{|c|c|c|c|c|c|c|c|}
\hline \multirow{2}{*}{ Dependent } & \multirow{2}{*}{ Independent } & \multirow{2}{*}{$\begin{array}{l}\text { Unstandardized } \\
\text { Beta }\end{array}$} & \multirow{2}{*}{$\underset{\text { Beta }}{\text { Standardized }}$} & \multirow{2}{*}{$\mathrm{T}^{1}$} & \multirow{2}{*}{$\operatorname{Sig}^{2}$} & \multicolumn{2}{|c|}{ Collinearity Statistics } \\
\hline & & & & & & Tolerance & VIF $^{3}$ \\
\hline \multirow{2}{*}{ ROS score $\left(R^{2}=0.319 ;\right.$ adjusted $\left.R^{2}=0.273\right)$} & (constant) & 2.27 & & 12.45 & 0.00 & & \\
\hline & water & 0.57 & 0.18 & 3.16 & $0.00 * *$ & 1.00 & 1.00 \\
\hline \multirow{2}{*}{ Preference value $\left(R^{2}=0.399 ;\right.$ adjusted $\left.R^{2}=0.359\right)$} & (constant) & 2.35 & & 32.89 & 0.00 & & \\
\hline & water & 0.36 & 0.53 & 2.40 & $0.00 * *$ & 1.00 & 1.00 \\
\hline
\end{tabular}

1 " $\mathrm{t}$ " means "significance test value". ${ }^{2}$ "Sig" means "Significance", $p<0.05^{*}, p<0.01^{* *}, p<0.001^{* * *}$. 3 "VIF" means "Variance expansion coefficient".

\section{Discussion}

\subsection{An Empirical Study on the Restoration Potential of Urban Landscape Forests for Adolescents}

Forest-derived visual stimulation can relieve stress and induce physical and mental relaxation $[21,65]$. Teenagers, who are an important group of urban landscape users, have more sources of stress than children and the elderly. This empirical study on the restoration potential of ULFs focused on teenagers. The results demonstrate that after viewing landscape forest pictures, the systolic blood pressure $(p<0.001)$, diastolic blood pressure $(p<0.01)$, and heart rate $(p<0.001)$ of the participants decreased significantly. The systolic blood pressure of female participants did not decrease significantly before and after viewing the urban landscape forest pictures, and the decrease in diastolic blood pressure was less significant than that of men, as men and women may have different responses to forest environments [66]. Men have stronger positive physiological responses to the visual stimulation of urban landscape forests. Studies have demonstrated that deciduous forests are the most ideal for reducing blood pressure [64]. Ginkgo is the most common deciduous forest tree species in Southwest China, which is consistent with the significant decrease in blood pressure in the participants after viewing the pictures of ginkgo forests. Although the blood oxygen values before and after viewing the urban landscape forest pictures decreased, the changes among men, women, and the overall group were not significant $(p>0.05)$. Blood oxygen level is an indicator of human metabolism. Under the short-term stimulation of the environment, the respiratory environment did not change, which could explain the changes in blood oxygen levels. Before and after viewing the urban landscape forest pictures, the overall heart rate of the participants decreased significantly $(p<0.001)$. Emotion can cause a change in the heart rate. When people feel anxious or excited, their 
heart rate increases [52]. One of the symptoms of blood pressure is an acceleration of the pulse [64], which means that the sympathetic and parasympathetic nervous systems of the participants changed significantly after viewing the urban landscape forest pictures. This is consistent with the significant reduction in the pulse rate observed after subjects entered a forest in forest therapy [67-69].

The psychological measurement results of this study demonstrate that after stress induction, the anxiety level of the participants decreased significantly and the restorative value increased significantly after viewing the urban forest landscape pictures, indicating that the experiment had a positive and restorative effect on the psychology of teenagers, which is consistent with previous studies indicating that green space can significantly reduce teenagers' negative emotions [6]. The population or urban area may affect the obtained ROS value [70]. In this study, the pre- and post-test ROS values of the male and female participants were similar, which may be due to the consistency of the volunteer group, who were teenagers in school. These results are different from those obtained in the elderly and professional groups [71]. Therefore, the results of this study indicate that ULFs could be used as a restorative environment in the future. This type of restorative environment has been demonstrated to decrease blood pressure, ease the heart rate, reduce anxiety, and help teenagers recover [72], supporting the first hypothesis.

\subsection{Spatial Elements and Restoration Potential of and Preferences for Urban Landscape Forests}

The overall restoration quality in green environments is always positively correlated with preferences [30,73,74], in which natural elements play a major role [75]. The results of this study are consistent with previous studies, indicating that landscape forest images with a water element have the highest restoration values and preference scores. In the urban green environment, landscape elements can be divided into natural and hard landscape components [1], in which the unconscious attention of users is described as "soft charm" in environmental psychology [64,76]. Some studies have verified and compared the health benefits of different soft charms of natural components in green space, such as the role of freshwater blue space in health promotion regarding the soft charm of therapeutic landscapes [77]. The results reveal that water is a significant predictor of the restoration value in ULFs, which is consistent with previous studies that found that natural water is a reliable predictor of restoration potential and preference [16,34]. The addition of water can enhance the attractiveness of the landscape. As a highly heterogeneous spatial element [78], it is the most easily perceived positive visual factor and can improve the quality of the recovery experience [79].

The results indicate that the elements of terrain, flowers, and shrubs did not have a significant influence on the restoration and preference value. We took the photographs and conducted the image synthesis during a deciduous and non-vegetation period; therefore, the spatial openness of the rendered images was lower and the visible details were clearer [80]. Unlike previous research objects, which mostly increased or decreased elements in vast green areas or open urban parks, the interface width and the perspective of the visual stimulation were different. The spatial scale may have an impact on the health benefits of viewing urban forest landscapes [81]. The scale in this study was relatively small and easy to interact with [82]. Since a more unified internal vegetation structure and biodiversity performance in different forests significantly induce stress recovery [83], when people continue to visit a green space after relaxing in it, they will focus more on their favorite spatial elements [79]. The vertical spatial fluctuation caused by appropriate terrain changes can provide tourists with different landscape experiences. In the extant literature, terrain is one of the most predictive factors of restoration [2,33], which is contrary to the conclusion of this study. This may be related to the type of landscape environment. Hands et al. [84] found that the quantitative diversity of landscape colors can improve the level of visual preference, photos with large color changes can attract a higher visual focus [85], and bright flowers are an important restoration attribute [34]; however, the flowers and shrubs used in images with a low degree of spatial openness cause certain visual obstacles [42], 
reducing the attractiveness. In addition, previous studies revealed that different spatial composition modes with the same elements may produce different results [86]. This study did not examine the physical and mental recovery and preference based on the difference between the element coverage ratio and the individual element heterogeneity; therefore, it is unclear whether there would be no significant prediction on the more detailed difference in terrain, flowers, and shrubs. However, this does not contradict the results of previous studies, as the psychological feedback obtained by the participants after viewing ULFs with different elements was positive. This answers the second hypothesis, indicating that, in ULFs, only water can be used as a significant predictor of health recovery support and preferences.

\subsection{Suggestions for Urban Landscape Forest Construction}

Promoting the development of urban forests is conducive to the ecosystem and human health $[87,88]$. The demonstration of the restorative capacity of ULFs in this study affirms the necessity of the construction of urban mesoscopic forests in health promotion and stress improvement. When increasing urban forest coverage, forest space designers should focus on the coordination of various landscape elements [89]. The results further indicate that water had a significant positive predictive effect on ULFs. When the elements of water, water and terrain, and water, terrain, and shrubs were added to the understory space, they produced a high restoration potential and aesthetic preference, which is in line with previous research on blue-green space [90,91]. This helps us to comprehensively consider the relevant optimization measures for the development of urban blue-green space and the construction of multiple ecological functions from the perspective of urban forest landscape planning [88]. Furthermore, it is particularly important to reconnect and create original natural elements in highly urbanized areas [92]. A landscape with a good spatial structure can have a positive impact on ecological services [93] and visual preferences [39]. Therefore, it is necessary to reasonably allocate the understory elements of green space to provide a higher restoration value and aesthetic quality. As such, the spatial layout of ULFs with an appropriate combination of natural and artificial water in the surrounding landscape is more restorative and attractive than that with other landscape elements and provides greater benefits when attempting to improve the quality of the experience [79].

\section{Conclusions}

The limited number of natural experiences in the urban environment may weaken people's ability to come into contact with nature [38], and the adjustment of physical, mental, and social stress through environmental strategies $[26,28]$ can improve the environment's restorative quality. This study explored the stress recovery effects of ULFs on adolescents based on different spatial elements. The results show that after 5 minutes of ULF picture viewing, the physiological and psychological state of adolescents had been restored and improved, which was specifically reflected in the decrease in blood pressure, heart rate, and anxiety and the improvement in recovery. This demonstrates that an ornamental forest landscape can improve the physiological and psychological recovery of adolescents. The results highlight that urban forest environments can regulate the bodies and minds of adolescents and provide scientific evidence for the beneficial effect of the conservation and construction of urban forest environments.

In addition, we evaluated the physical characteristics of different spatial elements of landscape forests. Water was found to be a significant predictor of recovery and preference values, indicating that the composition of spatial elements related to water in urban landscape forests may be an important environmental attribute in the creation of an environment with a high aesthetic and restoration value and that a space with water elements can be regarded as a more coherent urban environment that promotes positive emotions. Terrain, flowers, and shrubs had no significant impact on the overall recovery and preference values, which may be related to the research object, the research scale, and the degree of heterogeneity of the combinatorial elements. Our research results 
provide insights into urban green environment planning from a visual element perspective and supplement the limited evidence on different landscape element combinations in urban mountain forests [16] and urban lawn green spaces [34]. However, it should be emphasized that, given the uneven distribution of water resources around the world, based on the conclusions of this study, we believe that priority should be given to green natural resource management in water-deficient areas, and decision-makers should implement regional sustainability policies to protect biodiversity and landscape features [94]. When the conditions allow, natural water bodies, fountains, and other water-related elements should be used to design ULFs to promote human health and well-being.

\section{Limitations}

This study has some limitations. First, the research object was a group of teenagers, and other groups who use ULFs were not considered, which reduced the heterogeneity of the research object and the generalizability of the conclusions. Second, the extant literature indicates that integrated stimulation using a multi-sensory method is important to the design of a healthy environment $[34,95]$. This study focused on visual stimuli of ULFs that were easy to control and measured the recovery and preference values of single factors. In the future, the differentiation of single factors should be conducted, and quantitative research combined with auditory, olfactory, and tactile stimuli should be considered to guide the extraction of generalized recovery and preference spatial features in more detail. Furthermore, this study used images instead of a real forest environment in order to exclude outdoor confounding factors that may have affected the experimental results, such as noise, brightness, temperature, and humidity. However, this introduced such problems as the poor effectiveness of photographic reproduction [96], subjective bias in the use of photographic equipment [97], and deviations in the seasonal characteristics of landscape elements [98]. Multi-sensory experiences in real environments may be particularly important for the measurement of recovery potential and preferences. These stimuli were missing in this study. Future research should utilize real videos or scenes with stimuli from different spatial elements.

Author Contributions: Conceptualization, L.W. and Q.C.; methodology, L.W.; software, Q.D.; formal analysis, L.W. and Q.D.; investigation, S.L.; data curation, Q.D., W.J., and M.H.; writing—original draft preparation, L.W.; writing — review and editing, L.W.; visualization, L.W. and Q.D.; supervision, Q.C.; project administration, L.W. and S.L.; funding acquisition, Q.C.; project administration, Q.C and S.L. All authors have read and agreed to the published version of the manuscript.

Funding: Breakthrough bamboo and flower breeding materials and method innovation and new variety breeding (breeding research project) 2021yfyz0006.

Data Availability Statement: The data presented in this study are available on request from the corresponding author. The data are not publicly available due to privacy.

Conflicts of Interest: The authors declare that they have no conflict of interest.

\section{References}

1. Li, Y.; Rodiek, S.; Wu, C.; Wang, X.; Chen, Y. Stress recovery and restorative effects of viewing different urban park scenes in Shanghai, China. Urban For. Urban Green. 2016, 15, 112-122.

2. Deng, L.; Li, X.; Luo, H.; Fu, E.K.; Jia, Y. Empirical study of landscape types, landscape elements and landscape components of the urban park promoting physiological and psychological restoration. Urban For. Urban Green. 2019, 48, 126488. [CrossRef]

3. Milligan, C.; Bingley, A. Restorative places or scary spaces? The impact of woodland on the mental well-being of young adults. Health Place 2007, 13, 799-811. [CrossRef] [PubMed]

4. Wang, Y.; Qu, H.; Bai, T.; Chen, Q.; Jiang, M. Effects of Variations in Color and Organ of Color Expression in Urban Ornamental Bamboo Landscapes on the Physiological and Psychological Responses of College Students. Int. J. Environ. Res. Public Health 2021, 18, 1151. [CrossRef] [PubMed]

5. World Health Organization. Available online: https://www.who.int/ (accessed on 30 November 2021).

6. Xie, J.; Luo, S.; Furuya, K.; Sun, D. Urban parks as green buffers during the COVID-19 pandemic. Sustainability 2020, $12,6751$. [CrossRef] 
7. Lin, W.; Chen, Q.; Jiang, M.; Tao, J.; Zeng, Q. Sitting or Walking? Analyzing the Neural Emotional Indicators of Urban Green Space Behavior with Mobile EEG. J. Urban Health 2020, 97, 191-203. [CrossRef]

8. Patton, G.C.; Sawyer, S.M.; Santelli, J.S.; Ross, D.A.; Afifi, R.; Allen, N.B.; Arora, M.; Azzopardi, P.; Baldwin, W.; Bonell, C. Our future: A Lancet commission on adolescent health and wellbeing. Lancet 2016, 387, 2423-2478. [CrossRef]

9. Li, D.; Sullivan, W.C. Impact of views to school landscapes on recovery from stress and mental fatigue. Landsc. Urban Plan. 2016, 148, 149-158. [CrossRef]

10. Dyment, J.E.; Bell, A.C. Grounds for movement: Green school grounds as sites for promoting physical activity. Health Educ. Res. 2008, 23, 952. [CrossRef]

11. Bonell, C.; Wells, H.; Harden, A.; Jamal, F.; Fletcher, A.; Thomas, J.; Campbell, R.; Petticrew, M.; Whitehead, M.; Murphy, S. The effects on student health of interventions modifying the school environment: Systematic review. J. Epidemiol. Commun. Health 2013, 67, 667-681. [CrossRef]

12. Suzanne, T.; Danielle, T.; William, A.; Jason, G. Mental health benefits of interactions with nature in children and teenagers: A systematic review. J. Epidemiol. Commun. Health 2018, 72, 958-966.

13. Guski, R.; Smelser, N.J.; Baltes, P.B. Environmental stress and health. Int. Encycl. Soc. Behav. Sci. 2001, 12, 4667-4671.

14. Von Lindern, E.; Bauer, N.; Frick, J.; Hunziker, M.; Hartig, T. Occupational engagement as a constraint on restoration during leisure time in forest settings. Landsc. Urban Plan 2013, 118, 90-97. [CrossRef]

15. Hartig, T.; Catalano, R.; Ong, M. Cold summer weather, constrained restoration, and the use of antidepressants in Sweden. J. Environ. Psychol. 2007, 27, 107-116. [CrossRef]

16. Deng, L.; Luo, H.; Ma, J.; Huang, Z.; Li, X. Effects of integration between visual stimuli and auditory stimuli on restorative potential and aesthetic preference in urban green spaces. Urban For. Urban Green. 2020, 53, 126702. [CrossRef]

17. Giergiczny, M.; Czajkowski, M.; Ylicz, T.; Angelstam, P. Choice experiment assessment of public preferences for forest structural attributes. Work. Pap. 2015, 119, 8-23. [CrossRef]

18. Norouzi, N.; Fani, M. Comparison of Weak and Strong Theories of Environmental Sustainability in the Conceptual Context of Sustainable Development. Res. J. Ecol. Environ. Sci. 2021, 1, 108-122. [CrossRef]

19. Avolio, M.L.; Pataki, D.E.; Trammell, T.; Endter-Wada, J. Biodiverse cities: The nursery industry, homeowners, and neighborhood differences drive urban tree composition. Ecol. Monogr. 2018, 88, 259-276. [CrossRef]

20. Konijnendijk, C.; Nilsson, K.; Randrup, T.; Schipperijn, J. The Selection of Plant Materials for Street Trees, Park Trees and Urban Woodland. In Urban Forests and Trees; Springer: Berlin/Heidelberg, Germany, 2005. [CrossRef]

21. Song, C.; Ikei, H.; Kagawa, T.; Miyazaki, Y. Physiological and Psychological Effects of Viewing Forests on Young Women. Forests 2019, 10, 635. [CrossRef]

22. Vian, F.D.; Martínez, M.; Izquierdo, J.P. Citizen participation as a social shift tool in projects of urban fluvial space recovery: A case study in Spain. Urban For. Urban Green. 2018, 31, 252-260. [CrossRef]

23. Bieling, C. Cultural ecosystem services as revealed through short stories from residents of the Swabian Alb (Germany). Ecosyst. Serv. 2014, 8, 207-215. [CrossRef]

24. Bieling, C.; Plieninger, T.; Pirker, H.; Vogl, C.R. Linkages between landscapes and human well-being: An empirical exploration with short interviews. Ecol. Econ. 2014, 105, 19-30. [CrossRef]

25. Cmtc, A.; Cm, B.; Sr, A. What do people know? Ecosystem services, public perception and sustainable management of urban park trees in London, U.K. Urban For. Urban Green. 2019, 43, 126362.

26. Korpela, K.M. Place-Identity as a product of environmental self-regulation. J. Environ. Psychol. 1989, 9, 241-256. [CrossRef]

27. Korpela, K.M. Adolescents' favourite places and environmental self-regulation. J. Environ. Psychol. 1992, 12, 249-258. [CrossRef]

28. Korpela, K.M.; Hartig, T.; Kaiser, F.G.; Fuhrer, U. Restorative experience and self-regulation in favorite places. Environ. Behav. 2001, 33, 572-589. [CrossRef]

29. Korpela, K.M.; Ylén, M. Perceived health is associated with visiting natural favourite places in the vicinity. Health Place 2007, 13, 138-151. [CrossRef]

30. Van den Berg, A.E.; Koole, S.L.; van der Wulp, N.Y. Environmental preference and restoration: (How) are they related? J. Environ. Psychol. 2003, 23, 135-146. [CrossRef]

31. KORPELA, K.; HARTIG, T. RESTORATIVE QUALITIES OF FAVORITE PLACES-ScienceDirect. J. Environ. Psychol. 1996, 16, 221-233. [CrossRef]

32. Kaplan, R. Employees' reactions to nearby nature at their workplace: The wild and the tame. Landsc. Urban Plan. 2007, 82, 17-24. [CrossRef]

33. Nordh, H.; Alalouch, C.; Hartig, T. Assessing restorative components of small urban parks using conjoint methodology. Urban For. Urban Green. 2011, 10, 95-103. [CrossRef]

34. Wang, R.; Zhao, J.; Meitner, M.J.; Hu, Y.; Xu, X. Characteristics of urban green spaces in relation to aesthetic preference and stress recovery. Urban For. Urban Green. 2019, 41, 6-13. [CrossRef]

35. Coen, S.E.; Ross, N.A. Exploring the material basis for health: Characteristics of parks in Montreal neighborhoods with contrasting health outcomes. Health Place 2006, 12, 361-371. [CrossRef]

36. White, M.P.; Pahl, S.; Ashbullby, K.; Herbert, S.; Depledge, M.H. Feelings of restoration from recent nature visits. J. Environ. Psychol. 2013, 35, 40-51. [CrossRef] 
37. Stigsdotter, U.K.; Corazon, S.S.; Sidenius, U.; Refshauge, A.D.; Grahn, P. Forest design for mental health promotion-Using perceived sensory dimensions to elicit restorative responses. Landsc. Urban Plan. 2017, 160, 1-15. [CrossRef]

38. Macaulay, R.; Lee, K.; Johnson, K.; Williams, K. Mindful engagement, psychological restoration, and connection with nature in constrained nature experiences. Landsc. Urban Plan. 2022, 217, 104263. [CrossRef]

39. Gao, Y.; Zhang, T.; Zhang, W.; Meng, H.; Zhang, Z. Research on Visual Behavior Characteristics and Cognitive Evaluation of Different Types of Forest Landscape Spaces. Urban For. Urban Green. 2020, 54, 126788. [CrossRef]

40. Carter, B.T.; Luke, S.G. Best practices in eye tracking research. Int. J. Psychophysiol. 2020, 155, 49-62. [CrossRef]

41. Li, C.; Sun, C.; Sun, M.; Yuan, Y.; Li, P. Effects of brightness levels on stress recovery when viewing a virtual reality forest with simulated natural light. Urban For. Urban Green. 2020, 56, 126865. [CrossRef]

42. Kabisch, N.; Püffel, C.; Masztalerz, O.; Hemmerling, J.; Kraemer, R. Physiological and psychological effects of visits to different urban green and street environments in older people: A field experiment in a dense inner-city area. Landsc. Urban Plan. 2021, 207, 103998. [CrossRef]

43. Ikei, H.; Song, C.; Miyazaki, Y. Effects of olfactory stimulation by $\alpha$-pinene on autonomic nervous activity. J. Wood Sci. 2016, 62, 568-572. [CrossRef]

44. Joung, D.; Song, C.; Ikei, H.; Okuda, T.; Miyazaki, Y. Physiological and psychological effects of olfactory stimulation with D-Limonene. Adv. Hortic. Sci. 2014, 28, 90-94.

45. Jo, H.; Song, C.; Ikei, H.; Enomoto, S.; Kobayashi, H.; Miyazaki, Y. Physiological and Psychological Effects of Forest and Urban Sounds Using High-Resolution Sound Sources. Int. J. Environ. Res. Public Health 2019, 16, 2649. [CrossRef] [PubMed]

46. Ikei, H.; Song, C.; Miyazaki, Y. Physiological effects of wood on humans: A review. J. Wood Sci. 2017, 63, 1-23. [CrossRef]

47. Ikei, H.; Song, C.; Miyazaki, Y. Physiological effects of touching hinoki cypress (Chamaecyparis obtusa). J. Wood Sci. 2018, 64, 226-236. [CrossRef]

48. Liu, Y.; Hu, M.; Zhao, B. Audio-visual interactive evaluation of the forest landscape based on eye-tracking experiments. Urban For. Urban Green. 2019, 46, 126476. [CrossRef]

49. Lawson, B.R. The Language of Space; Architectural Press: London, UK, 2001.

50. Caas, I.; Téllez, E.; Téllez, F. A contribution to the assessment of scenic quality of landscapes based on preferences expressed by the public. Land Use Policy: Int. J. Cover. All Asp. Land Use 2009, 26, 1173-1181.

51. Berman, M.G.; Kross, E.; Krpan, K.M.; Askren, M.K.; Burson, A.; Deldin, P.J.; Kaplan, S.; Sherdell, L.; Gotlib, I.H.; Jonides, J. Interacting with nature improves cognition and affect for individuals with depression. J. Affect. Disord. 2012, 140, $300-305$. [CrossRef]

52. Wilkie, S.; Clouston, L. Environment Preference and Environment Type Congruence: Effects on Perceived Restoration Potential and Restoration Outcomes. Urban For. Urban Green. 2019, 46, 126476. [CrossRef]

53. Chalmin-Pui, L.S.; Roe, J.; Griffiths, A.; Smyth, N.; Heaton, T.; Clayden, A.; Cameron, R. "It made me feel brighter in myself"—-The health and well-being impacts of a residential front garden horticultural intervention. Landsc. Urban Plan. 2021, $205,103958$. [CrossRef]

54. Wang, Z.; Li, M.; Zhang, X.; Song, L. Modeling the scenic beauty of autumnal tree color at the landscape scale: A case study of Purple Mountain, Nanjing, China. Urban For. Urban Green. 2019, 47, 126526. [CrossRef]

55. Wei, L.; Zeng, C.; Lam, N.S.-N.; Liu, Z.; Tao, J.; Zhang, X.; Lyu, B.; Li, N.; Li, D.; Chen, Q. Study of the relationship between the spatial structure and thermal comfort of a pure forest with four distinct seasons at the microscale level. Urban For. Urban Green. 2021, 62, 127168.

56. Daniel, T.C.; Boster, R.S.; USDA Forest Service Research Paper RM-167, Range Experiment Station. Measuring Landscape Esthetics: The Scenic Beauty Estimation Method. 1976. Available online: https://www.fs.usda.gov/rmrs/publications/ measuring-landscape-esthetics-scenic-beauty-estimation-method (accessed on 30 November 2021).

57. Song, C.; Ikei, H.; Miyazaki, Y. Effects of forest-derived visual, auditory, and combined stimuli. Urban For. Urban Green. 2021, 64, 127253. [CrossRef]

58. Hoshiba, M.A.; Gonalves, F.D.; Urbintati, E.C. Respostas fisiológicas de estresse no matrinx (Brycon amazonicus) após exercício físico intenso durante a captura Physiological stress responses of matrinx (Brycon amazonicus) after chasing. Acta Amaz. 2009, 39, 445-451. [CrossRef]

59. Sung, J.; Woo, J.-M.; Kim, W.; Lim, S.-K.; Chung, E.-J. The Effect of Cognitive Behavior Therapy-Based Forest Therapy Program on Blood Pressure, Salivary Cortisol Level, and Quality of Life in Elderly Hypertensive Patients. Clin. Exp. Hypertens. 2012, 34, 1-7. [CrossRef] [PubMed]

60. Wang, Y.; Jiang, M.; Huang, Y.; Sheng, Z.; Huang, X.; Lin, W.; Chen, Q.; Li, X.; Luo, Z.; Lv, B. Physiological and Psychological Effects of Watching Videos of Different Durations Showing Urban Bamboo Forests with Varied Structures. Int. J. Environ. Res. Public Health 2020, 17, 3434. [CrossRef] [PubMed]

61. Spielberger, C.D.; Gorsuch, R.L.; Lushene, R.E. The State Trait Anxiety Inventory (STAI). Test Manual for Form X; Trad. It. S.T.A.I. Questionario di autovalutazione dell'ansia di stato e di tratto a cura di Pedrabissi e Santinello (1989); Consulting Psychologist Press: Palo Alto, CA, USA, 1970.

62. Julian, L.J. Measures of anxiety: State-Trait Anxiety Inventory (STAI), Beck Anxiety Inventory (BAI), and Hospital Anxiety and Depression Scale-Anxiety (HADS-A). Arthritis Care Res. 2011, 63, S467-S472. [CrossRef] 
63. Chen, H.T.; Yu, C.P.; Lee, H.Y. The Effects of Forest Bathing on Stress Recovery: Evidence from Middle-Aged Females of Taiwan. Forests 2018, 9, 403. [CrossRef]

64. Janeczko, E.; Bielinis, E.; Wójcik, R.; Wonicka, M.; Janeczko, K. When Urban Environment Is Restorative: The Effect of Walking in Suburbs and Forests on Psychological and Physiological Relaxation of Young Polish Adults. Forests 2020, 11, 591. [CrossRef]

65. Li, J.; Deng, J.; Pierskalla, C. Impact of attendees' motivation and past experience on their attitudes toward the National Cherry Blossom Festival in Washington, D.C. Urban For. Urban Green. 2018, 36, 57-67. [CrossRef]

66. Bielinis, E.; Takayama, N.; Boiko, S.; Omelan, A.; Bielinis, L. The effect of winter forest bathing on psychological relaxation of young Polish adults. Urban For. Urban Green. 2018, 29, 276-283. [CrossRef]

67. Park, B.J.; Tsunetsugu, Y.; Kasetani, T.; Kagawa, T.; Miyazaki, Y. The physiological effects of Shinrin-yoku (taking in the forest atmosphere or forest bathing): Evidence from field experiments in 24 forests across Japan. Environ. Health Prev. Med. 2010, 15, 18. [CrossRef]

68. Hiroko, O.; Harumi, I.; Song, C.; Maiko, K.; Takashi, M.; Takahide, K.; Li, Q.; Shigeyoshi, K.; Michiko, I.; Yoshifumi, M. Physiological and Psychological Effects of a Forest Therapy Program on Middle-Aged Females. Int. J. Environ. Res. Public Health 2015, 12, 15222-15232.

69. Lee, J.; Park, B.J.; Tsunetsugu, Y.; Kagawa, T.; Miyazaki, Y. Restorative effects of viewing real forest landscapes, based on a comparison with urban landscapes. Scand. J. For. Res. 2009, 24, 227-234. [CrossRef]

70. Takayama, N.; Korpela, K.; Lee, J.; Morikawa, T.; Tsunetsugu, Y.; Park, B.-J.; Li, Q.; Tyrväinen, L.; Miyazaki, Y.; Kagawa, T. Emotional, Restorative and Vitalizing Effects of Forest and Urban Environments at Four Sites in Japan. Int. J. Environ. Res. Public Health 2014, 11, 7207-7230. [CrossRef]

71. Hartig, T.; Staats, H. The need for psychological restoration as a determinant of environmental preferences. J. Environ. Psychol. 2006, 26, 215-226. [CrossRef]

72. Hourani, L.L.; Davila, M.I.; Morgan, J.; Meleth, S.; Ramirez, D.; Lewis, G.; Kizakevich, P.N.; Eckhoff, R.; Morgan, T.; Strange, L.; et al. Mental health, stress, and resilience correlates of heart rate variability among military reservists, guardsmen, and first responders. Physiol. Behav. 2020, 214, 112734. [CrossRef]

73. Herzog, T.R.; Maguire, P.; Nebel, M.B. Assessing the restorative components of environments. J. Environ. Psychol. 2003, 23, 159-170. [CrossRef]

74. Abkar, M.; Kamal, M.S.M.; Maulan, S.; Mariapan, M.; Davoodi, S.R. Relationship between the Preference and Perceived Restorative Potential of Urban Landscapes. HortTechnology 2011, 21, 514-519. [CrossRef]

75. Veitch, J.; Ball, K.; Rivera, E.; Loh, V.; Deforche, B.; Best, K.; Timperio, A. What entices older adults to parks? Identification of park features that encourage park visitation, physical activity, and social interaction. Landsc. Urban Plan. 2022, 217, 104254. [CrossRef]

76. Neale, C.; Aspinall, P.; Roe, J.; Tilley, S.; Mavros, P.; Cinderby, S.; Coyne, R.; Thin, N.; Bennett, G.; Thompson, C.W. The Aging Urban Brain: Analyzing Outdoor Physical Activity Using the Emotiv Affectiv Suite in Older People. J. Urban Health Bull. N. Y. Acad. Med. 2017, 94, 869-880.

77. Poulsen, M.N.; Nordberg, C.M.; Fiedler, A.; DeWalle, J.; Mercer, D.; Schwartz, B.S. Factors associated with visiting freshwater blue space: The role of restoration and relations with mental health and well-being. Landsc. Urban Plan. 2022, 217, 104282. [CrossRef]

78. Hoyle, H.; Hitchmough, J.; Jorgensen, A. All about the 'wow factor'? The relationships between aesthetics, restorative effect and perceived biodiversity in designed urban planting. Landsc. Urban Plan. 2017, 164, 109-123. [CrossRef]

79. Yu, G.A.; Tong, Z.A.; Ks, B.; Mu, B.; Yu, J.A.; Lu, Q.C. The spatial cognition of a forest landscape and its relationship with tourist viewing intention in different walking passage stages. Urban For. Urban Green. 2021, 58, 126975.

80. Franěk, M.; Petruálek, J.; Efara, D. Eye movements in viewing urban images and natural images in diverse vegetation periods. Urban For. Urban Green. 2019, 46, 126477. [CrossRef]

81. Lin, W.; Chen, Q.; Zhang, X.; Tao, J.; Zeng, C. Effects of Different Bamboo Forest Spaces on Psychophysiological Stress and Spatial Scale Evaluation. Forests 2020, 11, 616. [CrossRef]

82. Megahed, N.A.; Ghoneim, E.M. Antivirus-built environment: Lessons learned from Covid-19 pandemic. Sustain. Cities Soc. 2020, 61, 102350. [CrossRef] [PubMed]

83. Ghermandi, A.; Depietri, Y.; Sinclair, M. In the AI of the beholder: A comparative analysis of computer vision-assisted characterizations of human-nature interactions in urban green spaces. Landsc. Urban Plan. 2022, 217, 104261. [CrossRef]

84. Hands, D.E.; Brown, R.D. Enhancing visual preference of ecological rehabilitation sites. Landsc. Urban Plan. 2002, 58, 57-70. [CrossRef]

85. Huang, S.H.; Lin, Y.J. The effect of landscape colour, complexity and preference on viewing behaviour. Landsc. Res. 2019, 45, 1-14. [CrossRef]

86. Parsons, R. Conflict between ecological sustainability and environmental aesthetics: Conundrum, canard or curiosity. Landscape and Urban Planning. Landsc. Urban Plan. 1995, 32, 227-244. [CrossRef]

87. Hägerhäll, C.M.; Ode, Å.; Tveit, M.S.; Velarde, M.D.; Colfer, C.J.P.; Sarjala, T. Forests, human health and well-being in light of climate change and urbanisation. Iufro World 2010, 18, 601-608.

88. Tzoulas, K.; Korpela, K.; Venn, S.; Yli-Pelkonen, V.; Kazmierczak, A.; Niemela, J.; James, P. Promoting ecosystem and human health in urban areas using Green Infrastructure: A literature review. Landsc. Urban Plan. 2007, 81, 167-178. [CrossRef]

89. Li, X.; Chen, W.Y.; Hu, F.Z.Y.; Cho, F.H.T. Homebuyers' heterogeneous preferences for urban green-blue spaces: A spatial multilevel autoregressive analysis. Landsc. Urban Plan. 2021, 216, 104250. [CrossRef] 
90. Cracknell, D.; White, M.P.; Pahl, S.; Depledge, M.H. A preliminary investigation into the restorative potential of public aquaria exhibits: A UK student-based study. Landsc. Res. 2016, 42, 18-32. [CrossRef]

91. Lee, B.-G.; Lee, B.-L.; Chung, W.-Y. Mobile Healthcare for Automatic Driving Sleep-Onset Detection Using Wavelet-Based EEG and Respiration Signals. Sensors 2014, 14, 17915-17936. [CrossRef] [PubMed]

92. Witek, L. From Industry 4.0 to Nature 4.0-Sustainable Infrastructure Evolution by Design. In Advances in Human Factors, Sustainable Urban Planning and Infrastructure; Springer: Cham, Germany, 2018.

93. Haddad, N.M.; Brudvig, L.A.; Clobert, J.; Davies, K.F.; Gonzalez, A.; Holt, R.D.; Lovejoy, T.E.; Sexton, J.O.; Austin, M.P.; Collins, C.D.; et al. Habitat fragmentation and its lasting impact on Earth's ecosystems. Sci. Adv. 2015, 1, e1500052. [CrossRef] [PubMed]

94. Raposo, M.; Castanho, R.A.; Machado, M.; Castro, C.; Santos, P.; Pinto-Gomes, C. The Relevance of Vegetation Series on the Maintenance and Sustainability of Public Spaces in the Southwest Iberian Peninsula. In Landscape Architecture. The Sense of Places, Models and Applications; IntechOpen: London, UK, 2018; pp. 255-273.

95. Song, X.; Lv, X.; Yu, D.; Wu, Q. Spatial-temporal change analysis of plant soundscapes and their design methods. Urban For. Urban Green. 2018, 29, 96-105. [CrossRef]

96. Palmer, J.F.; Hoffman, R.E. Rating reliability and representation validity in scenic landscape assessments. Landsc. Urban Plan. 2001, 54, 149-161. [CrossRef]

97. Yamashita, S. Perception and evaluation of water in landscape: Use of Photo-Projective Method to compare child and adult residents' perceptions of a Japanese river environment. Landsc. Urban Plan. 2002, 62, 3-17. [CrossRef]

98. Junge, X.; Schupbach, B.; Walter, T.; Schmid, B.; Lindemann-Matthies, P. Aesthetic quality of agricultural landscape elements in different seasonal stages in Switzerland. Landsc. Urban Plan. 2015, 133, 67-77. [CrossRef] 